\title{
Effects of Ag addition on the Precipitation Hardening Behaviours and Corrosion properties of Al-Mg-Si Alloy
}

\author{
Ya-ya Zheng ${ }^{1,2}$, Bing-hui Luo ${ }^{1, *}$, Chuan He ${ }^{1}$, Zhi-wei Ren ${ }^{1}$, Yuan Yin ${ }^{1}$ \\ ${ }^{1}$ College of Materials Science and Engineering, Central South University, Changsha 410083, China; \\ ${ }^{2}$ Key Laboratory of Safety Design and Reliability Technology for Engineering Vehicle, \\ Changsha University of Science and Technology, Changsha 410114, China \\ "E-mail: luobinghui@csu.edu.cn
}

doi: $10.20964 / 2019.01 .30$

Received: 1 September 2018 / Accepted: 15 October 2018 / Published: 30 November 2018

\begin{abstract}
The effects of $\mathrm{Ag}$ on the microstructure, dynamic precipitation and corrosion properties of $\mathrm{Ag}-\mathrm{Mg}-\mathrm{Si}$ alloys were investigated, by using scanning electron microscopy (SEM), transmission electron microscopy (TEM), potentiodynamic polarization measurements and differential scanning calorimetry (DSC). The results show that with the increase in Ag content, the alloys peak hardness, the aging hardening speed and the electrical conductivity increase, but the softening speed decreases. The addition of Ag significantly accelerates the kinetic process of aging precipitation of $\mathrm{Ag}-\mathrm{Mg}$-Si alloy, improves the density and the thermodynamic stability of $\beta$ " phase $\left(\mathrm{Mg}_{5} \mathrm{Si}_{6}\right)$ and reduces the precipitation activation energy of the $\beta^{\prime \prime}$ and $\beta^{\prime}$ phase. The alloy without Ag exhibits severe local corrosion and intergranular corrosion; the alloy with $0.3 \mathrm{wt} . \% \mathrm{Ag}$ exists fewer grain boundary precipitates and exhibits a slight intergranular corrosion (IGC). The addition of excess Ag leads to the increase in the corrosion sensitivity.
\end{abstract}

Keywords: Ag-Mg-Si alloy; Ag content; thermodynamic; corrosion property; hardening behavior

\section{$\underline{\text { FULL TEXT }}$}

(C) 2019 The Authors. Published by ESG (www.electrochemsci.org). This article is an open access article distributed under the terms and conditions of the Creative Commons Attribution license (http://creativecommons.org/licenses/by/4.0/). 